\title{
Silicon Isotope Separation by two frequency IRMPD
}

\section{Separación isotópica de Si mediante la DMFIR con dos frecuencias}

\author{
M. Risaro ${ }^{1, *}$, V. D’Accurso ${ }^{1}$, J. Codnia ${ }^{1}$, M. L. Azcárate ${ }^{1,2}$ \\ 1. Departamento de Investigaciones en Láseres y Aplicaciones \\ UNIDEF (CITEDEF - CONICET), Buenos Aires, Argentina \\ 2.Investigadora CONICET, Argentina \\ ${ }^{(*)}$ E-mail: mrisaro@citedef.gob.ar
}

Received: 01/12/2016 Accepted: 08/08/2017

DOI: $10.7149 /$ OPA.50.3.49038

\begin{abstract}
:
InfraRed Multi-Photon Dissociation (IRMPD) is a highly selective laser isotope separation technique. This process consists of a sequential IR photon absorption from the ground vibrational state up to dissociation by a molecule that contains the isotope of interest. High dissociation threshold molecules require large intensity radiation fields. This drawback could be overcome by two-frequency IRMPD. In this technique, a low energy laser resonant with the first energy levels guarantees isotopic selectivity excitation and a second non-resonant large energy laser achieves molecular dissociation. The possibility of obtaining silicon laser isotopic enrichment using $\mathrm{SiF}_{4}$ as working molecule was investigated in this work. Two-frequency IRMPD of $\mathrm{SiF}_{4}$ with two $\mathrm{TEA} \mathrm{CO}_{2}$ single transverse mode lasers was studied in a molecular jet. The dissociation process was monitored with a Time-of-Flight mass spectrometer with UV multi-photon ionization. The excitation laser fluence and wavelength dependence of the isotopic dissociation estimator, $\alpha$, and the enrichment factor estimator, $\beta$, were determined and compared to those obtained in single-frequency IRMPD.
\end{abstract}

Key words: isotope separation, laser, silicon, infrared multiphoton dissociation.

\section{RESUMEN:}

La Disociación Multifotónica InfrarRoja (DMFIR) es un método de separación de isótopos con láser altamente selectivo el cual consiste en la absorción secuencial de fotones resonantes con un modo de vibración de la molécula que contiene el isótopo de interés, desde el estado fundamental hasta sobrepasar el umbral de disociación. Las moléculas con umbrales de disociación alto requieren láseres de alta energía. Esta desventaja puede superarse mediante la DMFIR con dos frecuencias. En esta técnica, un láser de baja energía, resonante con los primeros niveles vibracionales garantiza la selectividad isotópica del proceso y otro, menos restrictivo en sintonía, pero de alta fluencia produce la disociación molecular. En este trabajo se investigó la posibilidad de obtener enriquecimiento isotópico utilizando $\mathrm{SiF}_{4}$ como molécula de trabajo. Se estudió la DMFIR de $\mathrm{SiF}_{4}$ con dos frecuencias provenientes de dos láseres de $\mathrm{CO}_{2}$ TEA monomodo transversal en un jet molecular. Como sistema de detección se utilizó un espectrómetro de masas de tiempo de vuelo con ionización multifotónica UV. Se determinó el efecto de la variación de la fluencia y longitud de onda de los láseres de excitación y de disociación sobre los valores de los estimadores $\alpha$ y $\beta$ asociados a la eficiencia de la disociación y al grado de enriquecimiento isotópico obtenido, respectivamente, y se comparó con los resultados obtenidos en la DMFIR con una sola frecuencia.

Palabras clave: separación de isótopos, láser, silicio, disociación multifotónica infrarroja. 


\section{REFERENCES AND LINKS / REFERENCIAS Y ENLACES}

[1] T. Ruf, R. W. Henn, M. Asen-Palmer, E. Gmelin, M. Cardona, H.-J. Pohl, G. G. Devyatych, P. G. Sennikov. "Thermal conductivity of isotopically enriched silicon", Solid State Commun. 115, 243 (2000). https://doi.org/10.1016/S0038-1098(00)00172-1

[2] M. Kazan, G. Guisbiers, S. Pereira, M. R. Correia, P. Masri, A. Bruyant, S. Volz, P. Royer. "Thermal conductivity of silicon bulk and nanowires: Effects of isotopic composition, phonon confinement, and surface roughness", J. Appl. Phys. 107, 083503 (2010). https://doi.org/10.1063/1.3340973

[3] K. J. Dwyer, J. M. Pomeroy, D. S. Simons, K. L. Steffens and J. W. Lau, “Enriching ${ }^{28}$ Si beyond $99.9998 \%$ for semiconductor quantum computing", J. Phys. D: Appl. Phys. 47, 345105 (2014). https://doi.org/10.1088/0022-3727/47/34/345105

[4] J. J. Pla, F. A. Mohiyaddin, K. Y. Tan, J. P. Dehollain, R. Rahman, G. Klimeck, D. N. Jamieson, A. S. Dzurak, A. Morello, "Coherent Control of a Single ${ }^{29}$ Si Nuclear Spin Qubit", Physical Review Letters 113, 246801 (2014). https://doi.org/10.1103/PhysRevLett.113.246801

[5] Y. Yamada, H. Yamamoto, H. Ohba, M. Sasase, F. Esaka, K. Yamaguchi, H. Udono, S. Shamoto, A. Yokoyama, K. Hojou, "Local neutron transmutation doping using isotopically enriched silicon film", Journal of Physics and Chemistry of Solids 68, 2204-2208 (2007). https://doi.org/10.1016/i.jpcs.2007.08.056

[6] V.S. Letokhov, Non-Linear Laser Chemistry, Multiple-Photon Excitation, Springer Series of Chemical Physics, vol. 22, Springer-Verlag, Berlin, Heidelberg (1983).

[7] V. Y. Baranov, A. P. Dyad'kin, V. A. Kuzmenko, S. V. Pigulskiy; V. S. Mezhevov, V. S. Letokhov, V. B. Laptev, E. A. Ryabov, I. V. Yarovoi, V. B. Zarin, A. S. Podoryashy, "Production of carbon isotopes by laser separation", Proceedings of SPIE 4165, 314 (2000)

https://doi.org/10.1117/12.394137

[8] E. Santos, A. Belokurov, L. Azcárate, J. Codnia, C. Rosito, P. Mendoza. “Unidad fotónica de intracavidad para separación de isótopos de elementos livianos, integrada por láseres y fotorreactores". Patent AR074947B1 (2015).

[9] S. Arai, H. Kaetsu, S. Isomura, "Practical separation of silicon isotopes by IRMPD of $\mathrm{Si}_{2} \mathrm{~F}_{6}$ ", Applied Physics B 53, 199-202 (1991). https://doi.org/10.1007/BF00357136

[10] T. Noda, H. Suzuki, H. Araki H, M. Okada, "Si isotope separation for low activation”, Journal of Nuclear Materials 233- 237, 1496-1499 (1996). https://doi.org/10.1016/S0022-3115(96)00328-5

[11] Y. Okada, K. Takeuchi, "Infrared Laser Isotope Separation of Silicon with Molecular Beam of Hexafluorodisilane”, Journal of Nuclear Science and Technology 32, 413-415 (1997). https://doi.org/10.1080/18811248.1997.9733683

[12] A. Yokoyama, H. Ohba, M. Hashimoto, K. Katsumata, H. Akagi, T. Ishii, A. Ohya, S. Arai, "Silicon isotope separation utilizing infrared multiphoton dissociation of $\mathrm{Si}_{2} \mathrm{~F}_{6}$ irradiated with two-frequency $\mathrm{CO}_{2}$ laser lights", Applied Physics B 79, 883-889 (2004). https://doi.org/10.1007/s00340-004-1642-z

[13] J. L. Lyman, B. E. Newnam, T. Noda, H. Suzuki, “Enrichment of Silicon Isotopes with Infrared FreeElectron Laser Radiation", Journal of Physical Chemistry A 103, 4227-4232 (1999). https://doi.org/10.1021/ip984699v

[14] T. Noda, H. Suzuki, H. Araki, J. L. Lyman, B. E. Newnam, “Isotope separation of silicon and molybdenum using a free electron laser", Journal of Nuclear Materials 307-311, 715-718 (2002). https://doi.org/10.1016/S0022-3115(02)01265-5

[15] J. L. Lyman, S. D. Rockwood, "Enrichment of boron, carbon, and silicon isotopes by multiple-photon absorption of 10.6- $\mu$ m laser radiation", Journal of Applied Physics 47, 595-601 (1976). https://doi.org/10.1063/1.322619

[16] A. N. Alcaraz, J. Codnia, M. L. Azcárate. "Optimization of the infrared multiple-photon dissociation of $\mathrm{SiF}_{4}$ to increase the isotopic selectivity", Journal of Physics: Conference Series 274, 012091 (2011). https://doi.org/10.1088/1742-6596/274/1/012091

[17] J. Codnia, V. D'Accurso, A.N. Alcaraz, M.L. Azcárate, "Silicon Isotopes Enrichment”, Proceedings del 13TH Workshop on Separation Phenomena in Liquids and Gases. SPLG 2015, 77-84 ISBN 978-9871323-42-5, (2016). 
[18] J. Codnia, V. D'Accurso, M. L. Azcárate, "Silicon isotopes enrichment" Anales AFA 27, 35-39 (2016).

[19] J. Heicklen, V. Knight, "The infrared spectrum of $\mathrm{SiF}_{4}$ ”, Spectrochimica Acta 20, 295-298 (1964) https://doi.org/10.1016/0371-1951(64)80026-6

\section{Introduction}

At present, the electronics and microelectronics industries use natural silicon with an isotopic abundance of $92,2 \%$ of ${ }^{28} \mathrm{Si}, 4,7 \%$ of ${ }^{29} \mathrm{Si} \mathrm{y} 3,1 \%$ of ${ }^{30} \mathrm{Si}$. However, the use of silicon isotopes has aroused interest due to various applications. The removal of the ${ }^{29} \mathrm{Si}$ and ${ }^{30} \mathrm{Si}$ isotopes increases the thermal conductivity because of the reduction of the defects in the crystalline network [1,2]. On the other hand, there is a growing interest in obtaining highly enriched ${ }^{28} \mathrm{Si}$ on account of its up-and-coming applications in quantum computing. The presence of the ${ }^{29} \mathrm{Si}$ and ${ }^{30} \mathrm{Si}$ isotopes decreases the phase coherence time of qubits in quantum information systems. Long coherence times are achieved using highly enriched ${ }^{28} \mathrm{Si}[3]$ ]. On the other hand, ${ }^{29} \mathrm{Si}$ is used for studying information on nuclear-spin systems [4]. In addition, ${ }^{30} \mathrm{Si}$ is used in neutron transmutation doping to dope high purity silicon with phosphorus to fabricate high-power, high-voltage rectifiers and thyristors [5]. Therefore, it is necessary to find new methods to produce highly enriched and high purity silicon isotopes.

Laser based isotope separation techniques are promising. The InfraRed Multiple-Photon Dissociation (IRMPD) technique uses a tunable IR laser to selectively dissociate a particular isotopic species of a "working molecule" containing the element of interest [6]. As a result of the sequential absorption of photons resonant with a vibrational mode of the isotopic species, it subsequently dissociates. This technique has been the basis for the development of a $30 \%$ carbon isotope enrichment demonstration facility in Kaliningrad, Russia [7]. It has also been applied to the development of a tritium removal process [8].

Figure 1a schematizes the dependence of the potential energy on molecular internuclear distance. It can be observed that molecules behave as anharmonic oscillators and, as such, the vibrational levels' spacing decreases with increasing vibrational energy. In consequence, as the molecular excitation increases subsequent to the absorption of several IR photons, the radiation field will come out of resonance and the overall IRMPD yield will decrease. On the other hand, large laser fluences are needed to overcome the high dissociation thresholds in the IRMPD of some small and medium size molecules. This leads to a power broadening of the vibrational energy levels that reduces the dissociation selectivity. The use of two IR laser frequencies would help to overcome these undesired effects. As shown in Figure 1b, first, a low energy laser resonant with the first energy levels would excite the isotopic species of interest (excitation laser). This would preclude power broadening and thus guarantee the selectivity of the excitation. A second nonresonant high energy laser would then accomplish the dissociation of the selectively excited species (dissociation laser).

(a)

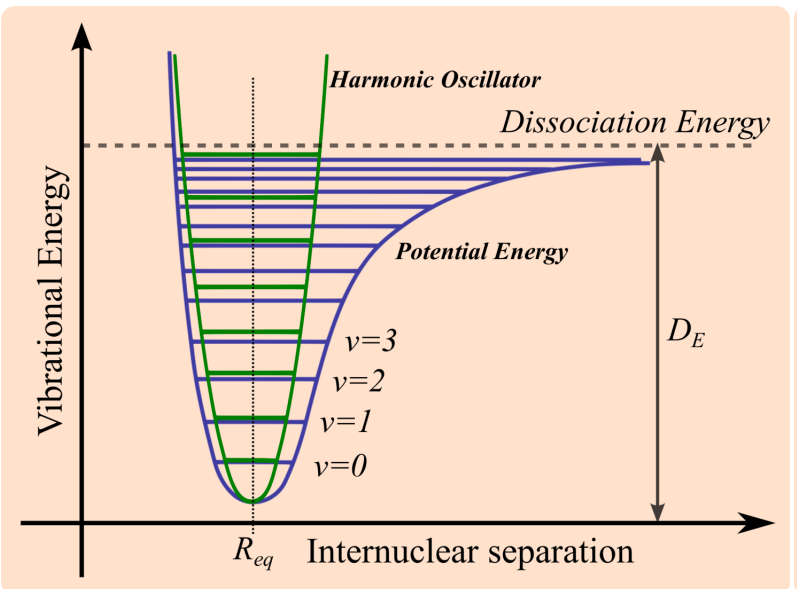

(b)

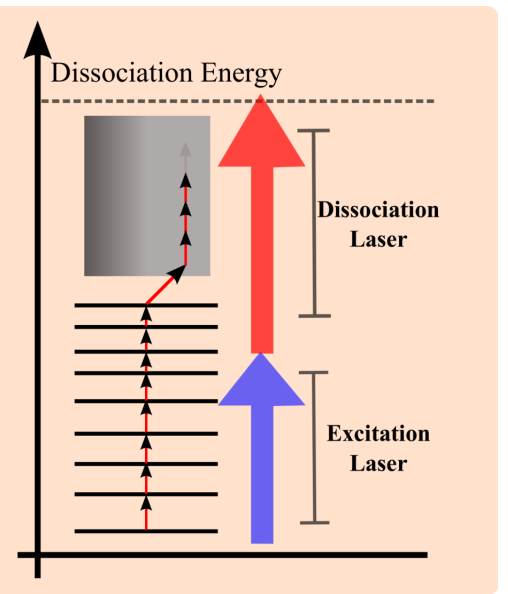

Fig. 1. Scheme of vibrational energy levels (a) and two-frequency IRMD of the $\mathrm{SiF}_{4}(\mathrm{~b})$. 
IRMPD with TEA $\mathrm{CO}_{2}$ lasers has been used with different working molecules for determining the isotopic selectivity of silicon containing compounds. The most encouraging results have been achieved with silicon hexafluorodisilane, $\mathrm{Si}_{2} \mathrm{~F}_{6}$ [9-14]. However, in order to avoid the decrease of the IRMPD efficiency for ${ }^{29} \mathrm{Si}$ and ${ }^{30} \mathrm{Si}$ due to the different isotopic mixtures of the product such as ${ }^{28} \mathrm{SiF}_{3}-{ }^{29,30} \mathrm{SiF}_{3}$, the use of working molecules containing only one silicon atom would be desirable. Silicon tetrafluoride, $\mathrm{SiF}_{4}$, is largely used in the semiconductor industry but it has been scarcely studied as a possible working molecule in the $\mathrm{Si}$ isotopes enrichment process by IRMPD. Lyman et al. obtained isotopic enrichment factors in ${ }^{29} \mathrm{Si}$ and ${ }^{30} \mathrm{Si}$ of 1.11 in batch studies of the IRMPD of $\mathrm{SiF}_{4}$ in mixtures with $\mathrm{H}_{2}$ with one $\mathrm{CO}_{2}$ laser frequency [15]. In previous works, we have used $\mathrm{SiF}_{4}$ as precursor molecule for silicon isotopics enrichment by one frequency IRMPD with a TEA $\mathrm{CO}_{2}$ laser [16-18]. In batch conditions with the addition of $\mathrm{H}_{2}$ as an acceptor gas to inhibit the fast recombination reaction of the $\mathrm{SiF}_{3}$ and $\mathrm{F}$ radicals generated in the first step of the IRMPD, we have obtained isotopic enrichment factors in ${ }^{29} \mathrm{Si}$ and ${ }^{30} \mathrm{Si}$ of 3.4 and 4.4 , respectively $[16,17]$. In a later study in a molecular jet $[17,18]$, isotopic enrichment factors in ${ }^{29} \mathrm{Si}$ and ${ }^{30} \mathrm{Si}$ of 5.6 and 8.4 , respectively, were obtained.

In this work, two-frequency IRMPD of $\mathrm{SiF}_{4}$ was carried out in a molecular jet. Two TEA $\mathrm{CO}_{2}$ single transverse mode lasers in a collinear configuration were used as the excitation and dissociation sources. The dissociation process was monitored with a Time-of-Flight mass spectrometer with non resonant UV multiphoton ionization. The time delay between the sample inlet and the excitation, dissociation and ionization lasers was varied so as to optimize the signal intensity. The two-frequency IRMPD was characterized by two estimators: the isotopic dissociation estimator, $\alpha$, and the isotopic enrichment factor estimator, $\beta$. In view of optimizing the isotopic enrichment process, the excitation laser fluence and wavelength dependence of $\alpha$ and $\beta$ was analyzed. The resultant enrichment factors were compared with those obtained with singlefrequency IRMPD.

\section{Method}

\section{2.a. Experimental}

The vibrational frequencies of the $v_{3}$ mode of the different isotopic species of $\mathrm{SiF}_{4}\left(1031.8 \mathrm{~cm}^{-1}, 1023 \mathrm{~cm}^{-1}\right.$ and $1014.4 \mathrm{~cm}^{-1}$ corresponding to ${ }^{28} \mathrm{SiF}_{4},{ }^{29} \mathrm{SiF}_{4}$ and ${ }^{30} \mathrm{SiF}_{4}$, respectively) (Figure 2) are quasi-resonant with the emission lines of the $9.4 \mu \mathrm{m}$ band of the $\mathrm{CO}_{2}$ laser [19]. A diagram of the experimental setup which has been detailed in reference [17] is shown in Figure 3.

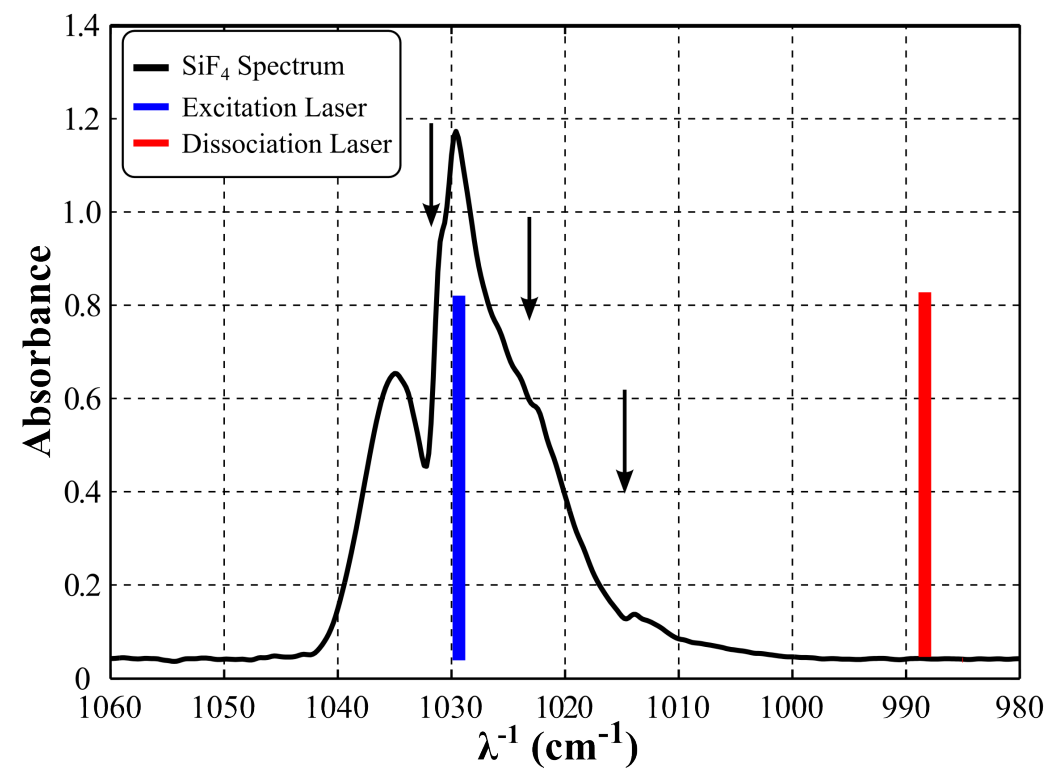

Fig.2. IR absorption spectrum of $\mathrm{SiF}_{4}$ with the natural isotopic abundance. The arrows indicate the vibrational frequencies of the $v_{3}$ mode of the different isotopic species. The blue and red bars correspond to the excitation and dissociation lasers' frequencies, respectively.

The gaseous sample of $\mathrm{SiF}_{4}$ entered the reaction chamber through a pulsed valve, Parker Hannifin Corporation, in the form of a jet. A Time-of-Flight mass spectrometer, Kore Technology Ltd., with UV multi- 
photon ionization with the fourth harmonic of a Nd:YAG laser, Spectra Physics, Quanta-Ray, Lab 170, (266 $\mathrm{nm}$ ), was used to monitor the dissociation process.

Two home-built TEA $\mathrm{CO}_{2}$ single transverse mode lasers were used as the excitation and dissociation sources (Fig.1b and Fig.2). Both IR laser beams were combined in a ZnSe beam splitter and entered the high vacuum reaction chamber $\left(\sim 210^{-7} \mathrm{Torr}\right)$ through a $\mathrm{KCl}$ window in a collinear configuration. Both beams were focused by a $20 \mathrm{~cm}$ focal length ZnSe lens into the center of the chamber where the mass spectrometer extractor is located. The lasers' output energies were determined with Gentec joulemeters. The sample injection and the excitation, dissociation and ionization pulses' timing was controlled by a digital delay generator, BNC 575-8C-COM. The signals from the ion multiplier and from two photodetectors used to monitor the IR and UV beams' intensities were recorded by an oscilloscope, Tektronix, DPO $71041 \mathrm{GHz}, 10$ GS/s. In order to distinguish the effect of the IRMPD, the signal acquisition was performed alternating samples irradiated with and without the IR lasers. Thus, the UV and IR lasers worked at repetition rates of $2 \mathrm{~Hz}$ and $1 \mathrm{~Hz}$, respectively. The excitation laser frequency was varied between $1054 \mathrm{~cm}^{-1}$ (9P12) and 992 $\mathrm{cm}^{-1}$ (10R48). The dissociation laser frequency was fixed far from resonance at $983 \mathrm{~cm}^{-1}(10 \mathrm{R} 32)$ and the energy at $125 \mathrm{~mJ}$.

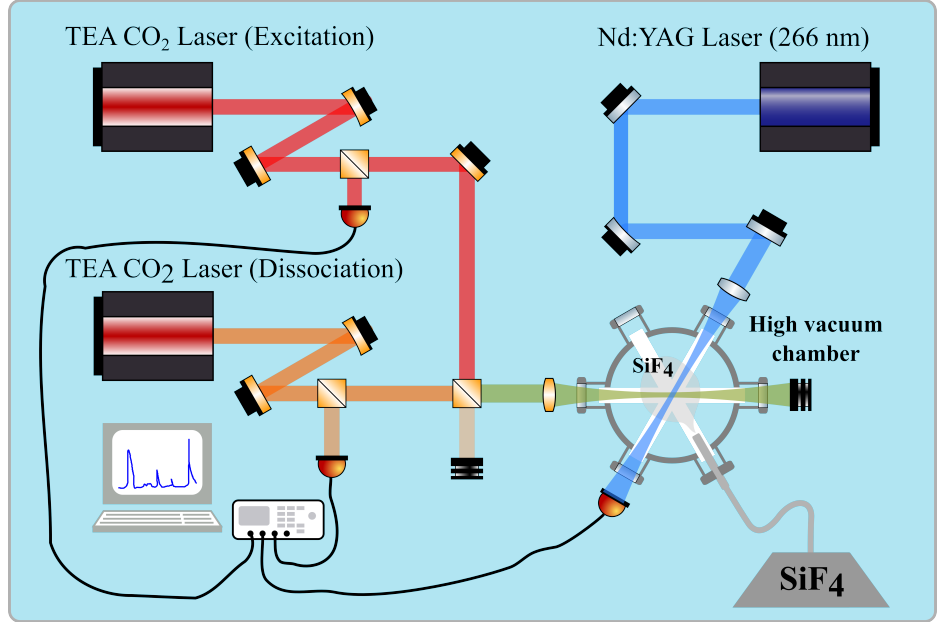

Fig.3. Experimental setup for the two-frequency IRPDM.

The time delay between the sample inlet and the dissociation and ionization lasers was varied so as to optimize the signal intensity. The two-frequency IRMPD was characterized by analyzing the isotope dissociation estimator, $\alpha$, and the isotope enrichment factor estimator, $\beta$, defined in Section $2 \mathrm{~b}$.

\section{2.b. Analysis of data}

The UV beam irradiation of the $\mathrm{SiF}_{4}$ sample, used as the ionization source of the Time-of-Flight mass spectrometer produces the following ionization and fragmentation pattern

$$
\begin{aligned}
& \mathrm{SiF}_{4}^{+} \\
& \mathrm{SiF}_{3}^{+}+\mathrm{F} \\
& \mathrm{SiF}_{4} \stackrel{h v_{U V} \longrightarrow}{\longrightarrow} \mathrm{SiF}_{2}^{+}+2 \mathrm{~F} \\
& \mathrm{SiF}^{+}+3 \mathrm{~F} \\
& \mathrm{Si}+4 \mathrm{~F}
\end{aligned}
$$

which is independent of the $\mathrm{Si}$ isotope present in the molecule.

Figure 4 shows a typical $\mathrm{SiF}_{4} \mathrm{UV}$ multi-photon ionization mass spectrum. It is characterized by the molecular fragmentation described by eq. 1 . As can be seen, the main peak corresponds to the $\mathrm{SiF}^{+}$ion, the height of which will be considered thereof as representative of the parent molecule. Ion peaks with $m / z=47,48$ and 49 correspond to ${ }^{28} \mathrm{SiF}^{+},{ }^{29} \mathrm{SiF}^{+}$and ${ }^{30} \mathrm{SiF}^{+}$, respectively. 


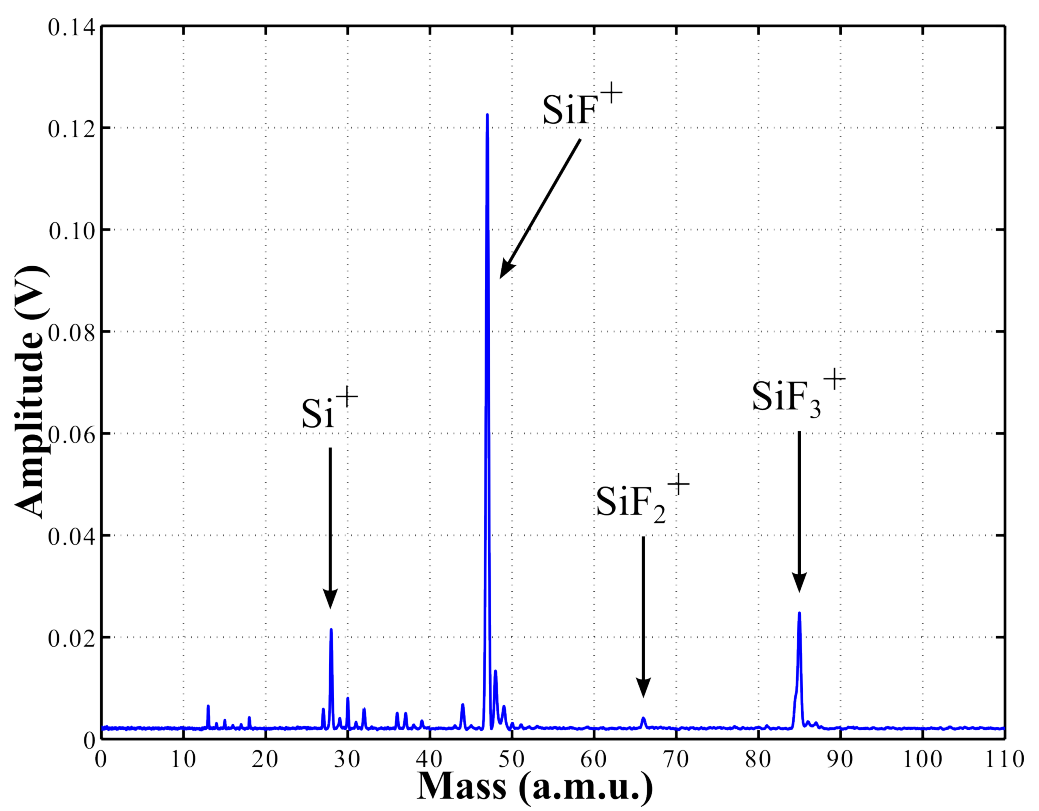

Fig.4. $\mathrm{SiF}_{4}$ mass spectrum obtained with $266 \mathrm{~nm}$ multi-photon ionization.

The concentration of $\mathrm{SiF}^{+}$ions obtained from the fragmentation of the initial $\mathrm{SiF}_{4}$ concentration is given by the fragmentation probability, $q$, which depends on the UV wavelength, $\lambda_{\mathrm{UV}}$, and fluence:

$$
\left[\mathrm{SiF}^{+}\right]_{\mathrm{UV}}=q\left[\mathrm{SiF}_{4}\right]_{0}
$$

where the subscript UV refers to the sample irradiated only with the UV laser.

The irradiation of the working molecule with IR radiation leads to molecular excitation and subsequent dissociation,

$$
\mathrm{SiF}_{4} \stackrel{h v_{I R}}{\longrightarrow} \mathrm{SiF}_{3}+\mathrm{F}
$$

The concentration of radicals of each isotopic species, $m / z=28,29,30$, produced through dissociation is given by:

$$
\left[{ }^{\mathrm{m}} \mathrm{SiF}_{3}\right]={ }^{m} f\left[\mathrm{~m}^{\mathrm{m}} \mathrm{SiF}_{4}\right]_{0}
$$

where ${ }^{m} f$ is efficiency of the process which depends on the wavelength, fluence and $\left.\left[{ }^{\mathrm{m} S i F}\right]_{0}\right]_{0}$ is the concentration of that species before irradiation. After the dissociation process the sample is irradiated with the UV laser beam which produces a similar ionization and fragmentation pattern:

$$
\mathrm{SiF}_{3} \stackrel{h v_{U V}}{\longrightarrow} \begin{aligned}
& \mathrm{SiF}_{3}^{+} \\
& \mathrm{SiF}_{2}^{+}+\mathrm{F} \\
& \mathrm{SiF}^{+}+2 \mathrm{~F} \\
& \mathrm{Si}^{+}+3 \mathrm{~F}
\end{aligned}
$$

The concentration of $\mathrm{SiF}^{+}$ions obtained is given by:

$$
\left[\mathrm{SiF}^{+}\right]=p\left[\mathrm{SiF}_{3}\right]
$$

where $p$ is the fragmentation and ionization probability of $\mathrm{SiF}^{+}$.

The concentration of $\mathrm{SiF}^{+}$ions obtained after IR an UV irradiation is described as:

$$
\begin{gathered}
{\left[{ }^{\mathrm{m}} \mathrm{SiF}^{+}\right]_{\mathrm{IR}}=p^{\mathrm{m}} f\left[{ }^{\mathrm{m}} \mathrm{SiF}_{4}\right]+\left(1-{ }^{\mathrm{m}} f\right) q\left[{ }^{\mathrm{m}} \mathrm{SiF}_{4}\right]_{0}} \\
\quad=p^{\mathrm{m}} f\left[{ }^{\mathrm{m}} \mathrm{SiF}_{4}\right]_{0}+\left(1-{ }^{\mathrm{m}} f\right) q\left[{ }^{\mathrm{m}} \mathrm{SiF}_{4}\right]_{0} \\
=q\left[{ }^{\mathrm{m}} \mathrm{SiF}_{4}\right]_{0}\left\{1+\left(\frac{p}{q}-1\right){ }^{\mathrm{m}} f\right\}
\end{gathered}
$$




$$
=\left[{ }^{\mathrm{m}} \mathrm{SiF}^{+}\right]_{\mathrm{UV}}\left\{1+\left(\frac{p}{q}-1\right){ }^{\mathrm{m}} f\right\}
$$

where the sub-index IR refers to the sample irradiated with the IR laser beam. In contrast with the dissociation factor $\mathrm{m} f$ which differs for each Si isotope, the fragmentation probabilities ( $q$ and $p$ ) of equation (7) are independent of the isotopic species.

The isotopic species dissociation estimator $(\alpha)$ derived from equation (7) is defined as,

$$
\mathrm{m}_{\alpha}=\frac{\left.{ }^{\mathrm{m}} \mathrm{SiF}^{+}\right]_{\mathrm{IR}}}{\left.{ }^{\mathrm{m}} \mathrm{SiF}^{+}\right]_{\mathrm{UV}}}-1=\left(\frac{p}{q}-1\right){ }^{\mathrm{m}} f
$$

The isotopic enrichment factor estimator $(\beta)$ is defined in a similar way:

$$
\beta_{29}=\frac{{ }^{28} f}{29 f}=\frac{{ }^{28} \alpha_{j}}{29 \alpha_{j}} \quad \text { y } \quad \beta_{30}=\frac{{ }^{28} f}{{ }^{30} f}=\frac{{ }^{28} \alpha_{j}}{{ }^{30} \alpha_{j}}
$$

Both estimators, $\alpha$ and $\beta$, were determined for two different lasers' irradiation configurations: cooperative and non-cooperative. In the cooperative configuration, $\mathrm{SiF}_{4}$ irradiation was performed with the excitation laser preceding the dissociation laser. In the non-cooperative configuration, the irradiation order was reversed.

\section{Results}

Figure 5 shows the dependence of $\alpha$ in the cooperative and non-cooperative configurations on the excitation laser frequency superimposed on the $\mathrm{SiF}_{4} \mathrm{IR}$ linear absorption spectrum. As it can be seen, the cooperative $\alpha$ values exhibit a broadband resonance peaked around $1030 \mathrm{~cm}^{-1}$. This result is consistent with the ${ }^{28} \mathrm{SiF}_{4}$ $v_{3}$ mode absorption maximum frequency at $1031.8 \mathrm{~cm}^{-1}$.

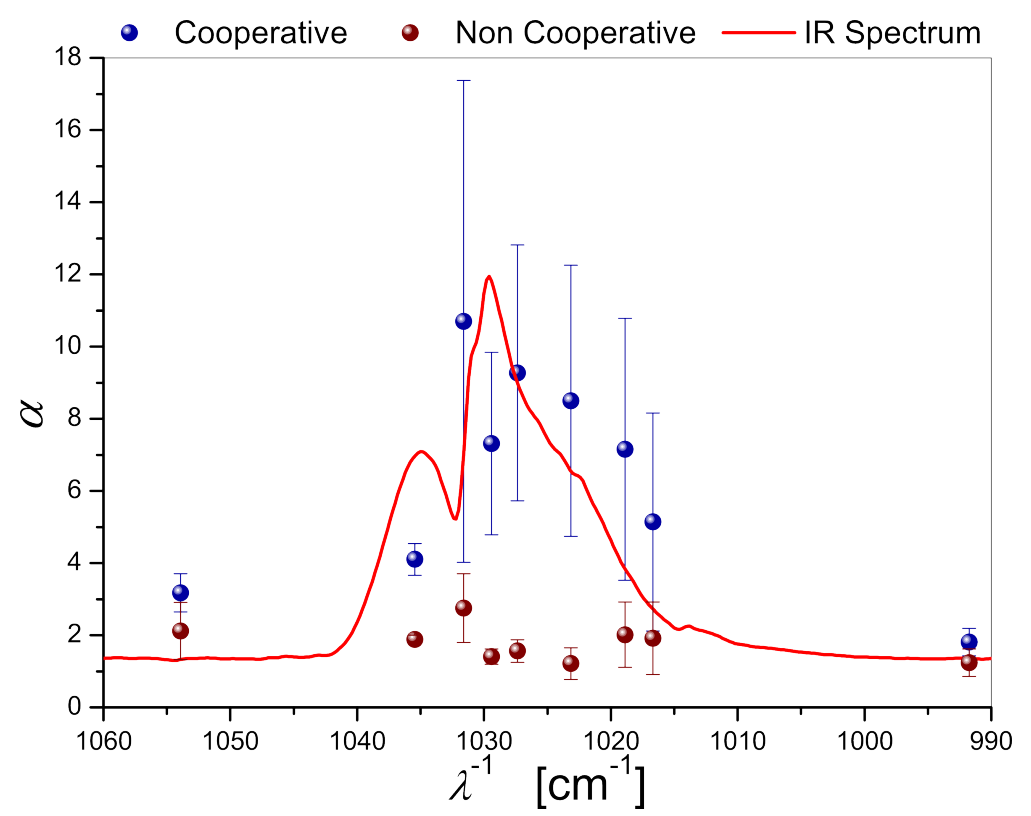

Fig.5. Dependence of the dissociation isotope estimator, $a$, on the excitation laser frequency. The dissociation frequency was fixed at $983 \mathrm{~cm}^{-1}$.

A comparison between single and two-frequency IRMPD is shown in Figure 6. As can be seen an enhancement up to ten times of the isotopic dissociation is obtained with the two-frequency technique. It must be pointed out as well that the two-frequency spectrum presents a lower red shift of about $4 \mathrm{~cm}^{-1}$ compared to the $\sim 12 \mathrm{~cm}^{-1}$ of the single-frequency IRMPD. This result is indicative of a clear optimization of the molecular excitation and dissociation process. 


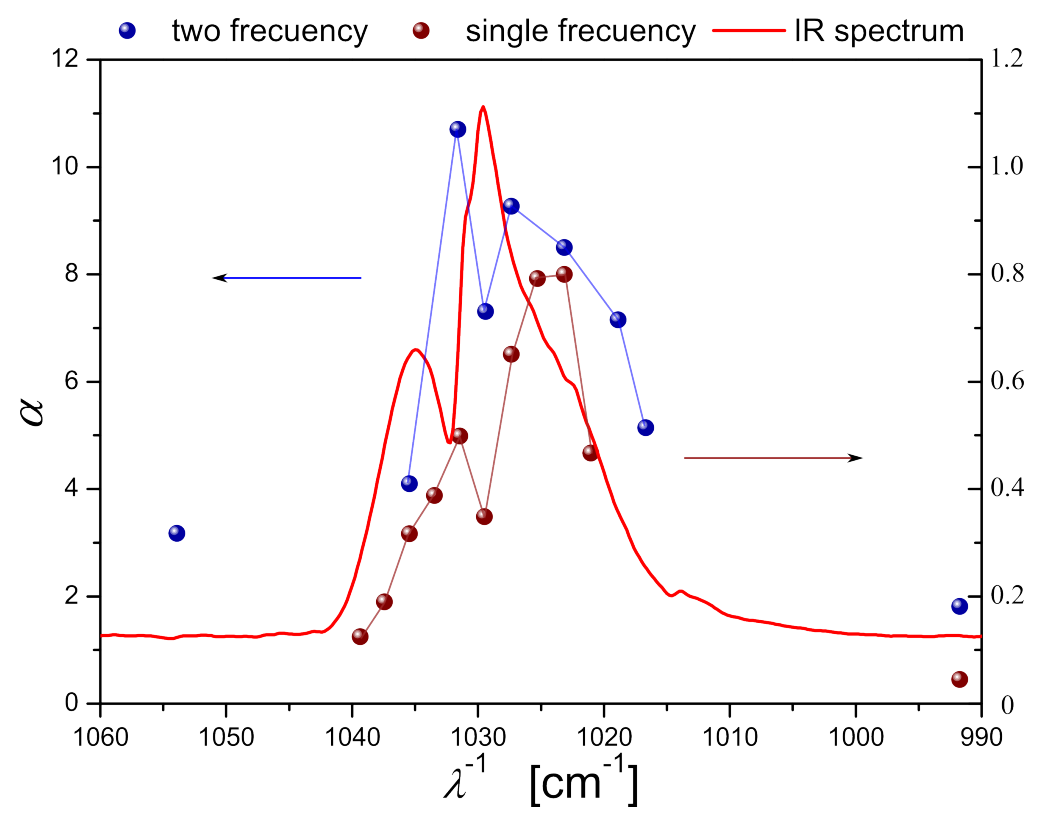

Fig.6. Comparison between single and two-frequency IRMPD isotope dissociation.

The isotopic enrichment factor estimator $\left(\beta_{30}\right)$ dependence on the excitation laser frequency, is shown in Figure 7. Similar behaviours to that of the $\alpha$ estimators' values of the cooperative and non-cooperative configurations were obtained. Values of $\beta_{30} 2.5$ times larger than those obtained with single-frequency IRMPD were determined.

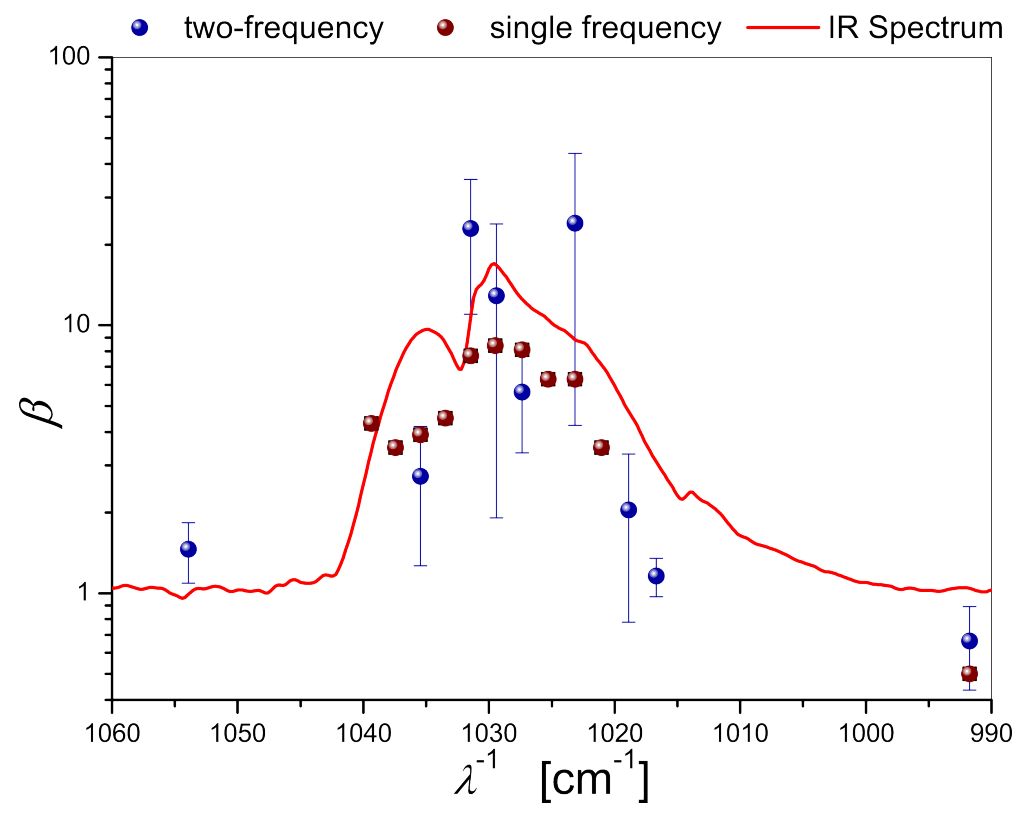

Fig.7. Comparison between single and two-frequency IRMPD isotopic enrichment factor estimator $\left(\beta_{30}\right)$.

\section{Conclusions}

Two-frequency IRMPD of $\mathrm{SiF}_{4}$ was studied in a molecular jet. The dissociation process was characterized by two estimators: the isotopic dissociation estimator, $\alpha$, and the isotopic enrichment factor estimator, $\beta$. These estimators were determined for two different lasers' irradiation configurations: cooperative and noncooperative. In the cooperative configuration, the excitation laser preceded the dissociation laser while in the non-cooperative configuration, the irradiation order was reversed. Both estimators' dependences on the excitation laser fluence and wavelength were analyzed. The resultant enrichment factors were compared with those obtained with single-frequency IRMPD. 
The fraction of dissociated molecules $\left({ }^{28} f\right)$ with two-frequency IRMPD was found to be 8 times larger than that obtained by single-frequency IRMPD.

The isotopic enrichment factor estimator $\left(\beta_{30}\right)$ of the $\mathrm{SiF}_{4}$ IRMPD was determined for irradiation with different emission lines of the $9.4 \mu \mathrm{m}$ band of a TEA $\mathrm{CO}_{2}$ laser. The two-frequency IRMPD produced a 2.5 times enhancement in the $\beta_{30}$ value with respect to the single-frequency IRMPD value.

The two-frequency IRMPD has proved to be a promising technique for laser isotopic enrichment of molecules with high dissociation threshold.

\section{Acknowledgements}

Authors wish to acknowledge financial support from the Ministry of Defence of Argentina through grant PIDDEF 09/11 and 02/2014.

Parts of this work were presented at the $\{$ RIAO/OPTILAS 2016\} in $\{$ PS4_37\}, $\{2016\}$. 